\title{
Análisis de las ciencias sociales en América Latina. Una introducción ${ }^{*}$
}

\author{
Julio Mejía Navarrete \\ Universidad Nacional Mayor de San Marcos, Lima, Perú \\ jvmena@hotmail.com
}

\begin{abstract}
RESUMEN
El estudio examina el desarrollo de las ciencias sociales contemporáneas en América Latina y subraya su originalidad en la gestación de propuestas teóricas, en particular de la colonialidad del poder. Explica la crisis de las ciencias sociales en los ochenta y la emergencia de un nuevo debate cognoscitivo. Proceso que envuelve la revisión y crítica de los fundamentos básicos que dieron origen al conocimiento desde el siglo XV y que signan el advenimiento de otro discurso más allá de los límites de la modernidad.
\end{abstract}

Palabras clave: Conocimiento social, epistemología, modernización global, América Latina

\section{Analysis of the social sciences in Latin America: An introduction}

\begin{abstract}
The study examines the development of the contemporary social sciences in Latin America and underlines its originality in the creation of theoretical proposals, specially of the power coloniality. It explains the social sciences crisis in the 1980s and the appearance of the new cognitive debate. A process that envelops the revision and criticism of the basic foundations that gave rise to the knowledge since the fifteenth century, and which signifies the advent of another discourse beyond the limits of modernity.
\end{abstract}

KeYworDs: Social knowledge, epistemology, global modernization, Latin America

\footnotetext{
* El presente trabajo es una revisión y ampliación del artículo «De la crisis a la emergencia de un nuevo debate: Las ciencias sociales contemporáneas en AL. Una aproximación desde el Perú», publicado en Espacio Abierto: Cuaderno Venezolano de Sociología, Vol. 29(1), 68-85. La primera versión del artículo fue parte de una ponencia presentada en el Primer Congreso Nacional de Investigación organizada por la Universidad Ricardo Palma en octubre del 2019.
} 


\section{Introducción}

Actualmente, América Latina se encuentra inmersa en cambios substanciales que afectan todos los ámbitos de su existencia y el conocimiento social. El desarrollo de las ciencias sociales en el continente desde las últimas décadas del siglo pasado se correlaciona al proceso transformativo impulsado por la expansión de modernización global.

De modo específico, en los años ochenta con la gestación de la globalización, en medio de la crisis del socialismo existente, la derrota de los movimientos sociales y la erupción de un pensamiento neoliberal, condicionaron una aguda crisis en las ciencias sociales de América Latina. Asimismo, a partir de los noventa en medio de una intensa deslegitimación del neoliberalismo, una reacción mundial contraria y la emergencia de un nuevo horizonte de sentido por un mundo más justo, irrumpe con mucha significación y alcance internacional un nuevo debate en las ciencias sociales de Latinoamérica que cuestionan la hegemonía de la perspectiva eurocéntrica.

Las ciencias sociales en América Latina pasaron por varios momentos de crisis y recuperación. La particularidad del momento contemporáneo tiene que ver con la profunda crisis epistemológica que arrastra los fundamentos básicos que explican el desenvolvimiento del conocimiento en la modernidad. La posibilidad del devenir de las ciencias sociales en la región acarrea la revisión y cuestionamiento de los principios rectores que dieron origen al conocimiento desde el siglo $\mathrm{XV}$ y que signan el advenimiento de otro discurso epistémico más allá de los límites de la modernidad.

El artículo se inspira en la obra de Aníbal Quijano, de modo específico, se rescatan sus trabajos referidos a la situación de las ciencias sociales «Notas sobre los problemas de la investigación social en América Latina» (1990) y «un nuevo debate en América Latina» (2014a). Estudios que delimitan originalmente la trayectoria laberíntica de las actuales ciencias sociales ${ }^{1}$. No obstante, lo anterior, aquí se bosquejan algunas ideas inaugurales con la intensión de propiciar un debate mayor del desarrollo del conocimiento social.

En ese sentido, el texto se divide en tres partes centrales, la crisis de las ciencias sociales en los ochenta, la renovación de las bases epistemológicas y la emergencia de un nuevo debate cognoscitivo.

\section{Crisis de las ciencias sociales}

Las ciencias sociales de América Latina durante las últimas décadas del siglo XX se encontraban definidas por una intensa crisis con sendas repercusiones a nivel mundial y

\footnotetext{
1 Otros trabajos fundamentales de Aníbal Quijano «Imagen y tareas del sociólogo en la sociedad peruana» (1965), «Sociedad y sociología en América Latina» (1981), «Sociedad, poder y sociología en el Perú» (1982) y «Profesión y oficio de la sociología» (1992).
} 
del propio conocimiento que trazó la modernidad. Aníbal Quijano (1990) ha acopiado con mucha lucidez la situación crítica del conocimiento social. El conocimiento social atravesaba por una "crisis de paradigmas" y una "crisis de problemática», los modelos teóricos eran insuficientes para explicar la realidad de América Latina y las interrogantes que formulan la investigación no permitían reproducir niveles significativos y ofrecer una imagen adecuada de la sociedad. América Latina en los ochenta y noventa se encontraba marcado por una "agenda de fracasos», por el agotamiento del enfoque desarrollista cepalino, el cuestionamiento de la teoría de la dependencia y al estructuralismo, la crisis del «socialismo realmente existente», crisis del marxismo y, sobre todo, por el impulso de la globalización neoliberal (Torres-Rivas, 2008).

Por un lado, la «crisis de paradigmas» se formuló como parte de la metamorfosis de la modernidad y cuyo agotamiento envolvían los fundamentos epistemológicos que sustentaron los modelos de conocimientos impuestos en todo el mundo desde el siglo XVI. La «crisis de paradigmas» de las ciencias sociales en nuestro continente tenía varios matices interrelacionados que es preciso examinar: crisis epistemológica, crisis de la teoría general y crisis de la teoría específica de América Latina.

La crisis epistemológica de las ciencias sociales en América Latina es la crisis de la subjetividad de la propia modernidad. Hay razones para pensar que la sociedad moderna tiene limitaciones, con su consiguiente forma de producir conocimiento, no solo está en cuestionamiento la teoría de las ciencias sociales sino las propias bases cognoscitivas que corresponden a la forma de generar los modelos de conocimientos, lo que se ha venido definiendo como el paradigma cartesiano-newtoniano que tuvo hegemonía desde los orígenes de la modernidad. De modo concreto, las ciencias sociales se fueron instituyendo desde fines del siglo XVIII, en particular se desarrollan a imagen semejante de la ciencia física. En la que dominaba la perspectiva mecanicista que entendía la realidad como la suma de las partes y se explicaba por el funcionamiento esencia de los componentes, rehusando considerar la importancia de la totalidad histórica-social. Dentro de una visión determinista que considera la realidad en función de una específica "causalidad lineal y univoca» aislada de las redes de las relaciones constitutivas y del contexto social. El conocimiento se concebía en forma independiente de las circunstancias de su observación, sobre la base de una separación absoluta entre sujeto y objeto (Morin, 1995, p. 23).

Hay una trayectoria que empieza a conformarse más allá de la modernidad, muchos elementos indican que algo está acabando y algo nuevo comienza a tomar forma. Las ciencias sociales moderna, fundada en el modelo cartesiano-newtoniano, está en un proceso de transición hacia una nueva forma de racionalidad formada en la complejidad (Wallerstein, 2001, p.188). La configuración de un paradigma epistemológico emergente tiene su desarrollo en la teoría de catástrofes y la teoría del caos, la teoría de las estructuras disipativas de Prigogine, la autoorganización de Von Foerster, la teoria 
sinergética de Haken y la teoría autopoiética de Humberto Maturana. Todos desarrollan una concepción basada en un futuro indeterminado, los equilibrios son más bien las excepciones y, por lo tanto, la racionalidad de la complejidad implica que los fenómenos se enfrentan a un conjunto de sucesivas alternativas, no a leyes universales preestablecidas que gobiernan el mundo (Santos, 2006; Martínez, 1993; Borda, 2003), lo que Ilya Prigogine denomina «EI fin de las certidumbres» (1997). Como nunca en su historia, América Latina participa de este cambio epistemológico mundial fundado en la complejidad, las contribuciones científicas de Humberto Maturana (2006) y Pablo Gonzales Casanova (2004) para entender el conocimiento desde la propia realidad contextual de América Latina y como una totalidad sistémica.

De modo paralelo, desde mediados de los setenta las ciencias sociales en América Latina se caracterizan por una etapa de crisis de la teoría general, después de la hegemonía del marxismo y la teoría de la dependencia, hay una ruptura de consensos categoriales básicos (Vergara y Gomáriz, 1993; Sonntag, 1988). Destacaba la ausencia de una teoría de la sociedad, de un sistema de principios cognoscitivos básicos que permita entender la sociedad en su conjunto. Las ciencias sociales en América Latina devinieron en disciplinas «sin un núcleo conceptual común» (Giddens, 2000, p.16), situación que expresa la perplejidad que dominaba en el conocimiento social en América Latina y el mundo. También Niklas Luhmann se refiere al fracaso de elaborar una teoria sistemática como el rasgo central de los 100 años de desarrollo de la sociologia (2007). Con razón, Immanuel Wallerstein señalaba que las ciencias sociales tienen grandes limitaciones en el estudio de la vida social, durante mucho tiempo las ciencias sociales se han pasado repensando los mismos conceptos, ya no permiten comprender las grandes transformaciones deI mundo contemporáneo, es necesario «Impensar las ciencias sociales» con la esperanza de estimular la creación de un nuevo paradigma a largo plazo (Wallerstein, 1999).

Otro aspecto de las ciencias sociales contemporáneas es la crisis de teoría específica sobre América Latina, desapareció la capacidad de establecer una explicación de su desarrollo y naturaleza, en cambio se consiguió el estudio de un buen número de temáticas específicas. Carecíamos de una visión global de América Latina, a diferencia de los ańos los sesenta y setenta que produjeron trabajos totalizadores de la sociedad, por ejemplo en el Perú destacan François Bourricaud (1967), Aníbal Quijano (1967) y Julio Cotler (1978). Lo que ha desarrollado las ciencias sociales en los ochenta son estudios puntuales y parciales sobre la ecología, la desigualdad social, la ciudadanía, la heterogeneidad estructural, la migración, la informalidad, la pobreza, la violencia, los efectos culturales de la televisión, la intención del voto electoral, las creencias religiosas, etc. Las ciencias sociales han avanzado en sus logros, en el estudio de fenómenos específicos, de la sociedad en su conjunto aún sabemos poco, cosas puntuales. Aunque las ciencias sociales muestran un desarrollo sostenido, sigue siendo desigual y parcial. 
En América Latina, las ciencias sociales desarrollaron una serie de temáticas concretas, que a pesar de sus desarrollos conceptuales no logran elevarse como nuevas propuestas teóricas por la falta de articulación con los planos conceptuales más generales y la limitación en el desarrollo de investigaciones empíricas (Vergara y Gomáriz, 1993). Sin embargo, la práctica de investigación en América Latina es primordialmente descriptiva, resaltaba la caracterización de los objetos de estudio y la clasificación de los datos, la realidad se comprendía como un conjunto de factores, lo que Wrigt Mills denominó empirismo abstracto (1986, p. 68.) y Anthony Giddens refirió que la «investigación ha degenerado en empirismo puro» (2000, p.13), son estudios orientados por una problemática «urgente» y por ser estudios aplicados, los cuales son fuertemente dependiente de organismos de promoción social (Mejía, 2002).

Por otro lado, «la crisis de problemática en el conocimiento social» (Quijano, 1990, p. 20) se refiere a las interrogantes de la investigación que no permiten dar cuenta de una realidad cambiante y a su dependencia cognoscitiva de los viejos paradigmas en cuestión, en un contexto complejo que envuelve la crítica de los propios fundamentos epistemológicos de los modelos de producción cognoscitiva desarrollados. La crisis de problemática expresa las limitaciones y déficits para formular cuestiones y preguntas esenciales que sigan el movimiento cambiante del objeto de análisis, de las transformaciones permanentes de la sociedad de América Latina impulsadas, esencialmente, por el proceso de globalización del capital. Igualmente, las preguntas de la investigación social se mostraban encapsuladas y dominadas por teorías que operaban desde tradicionales esquemas conceptuales eurocéntricos que no permitían comprender las transformaciones cambiantes de la realidad, dejando amplios espacios, niveles y dinámicas emergentes de los hechos sociales.

\section{Renovación epistemológica del pensamiento}

La hegemonía universal del patrón moderno del conocimiento social empezó a hacer crisis en las últimas décadas del siglo pasado, trazaba un itinerario epistemológico que delimitaban contenidos que se conformaban más allá de la propuesta newtoniana. Se abría una etapa de bifurcación teórica del pensamiento moderno, el cual mostraba que el sistema puede ir en varias direcciones, su lógica, estabilidad y sentido se ha roto. La episteme moderna prendada de los tejidos del modelo cartesiano-newtoniano deviene en un proceso de crítica y renovación teórica. Immanuel Wallerstein lo ha precisado de la siguiente forma: «lo que es esencial poner de relieve en los estudios de la complejidad es que de ningún modo rechazan el análisis científico, solo el determinismo newtoniano» (Wallerstein, 2004, p.194). 
En primer lugar, la respuesta crítica inmediata a la razón newtoniana es el desarrollo de ciertas propuestas inspiradas en la posmodernidad y los estudios culturales que expresaban un cierto escepticismo e irracionalismo. Entre sus representantes más connotados destacan autores como Jesús Martín-Barbero, George Yúdice, Beatriz Sarlo y, sobre todo, Néstor García Canclini que dominaban el contexto cultural de la región. La emergencia de los estudios culturales se expresaba en un momento de crisis y cierta desilusión de las ciencias sociales, emprendía cuando la producción teórica de los autores posmodernistas dominaba el escenario teórico, aunque ya mostraba claros signos de agotamiento en América Latina ${ }^{2}$. En ese contexto, los estudios culturales son una expresión del legado posmoderno que surge como una respuesta al cuestionamiento y crisis del conocimiento social y se formula con la intención de «superar las ciencias sociales clásicas» latinoamericanas (García Canclini, 1993, pp. 5-8).

Las perspectivas de la posmodernidad y los estudios culturales en América Latina han impulsado el giro hermenéutico, Jesús Martín-Barbero (2001) se refiere a las dos características centrales «uno de rechazo a la razón totalizante y su objeto (...) y otro de búsqueda de una unidad no violenta de lo múltiple». Precisamente, el rechazo a la razón newtoniana, combina con la libre reflexión de las exigencias científicas que Clifford Geertz (1990) calificaba de «literaturización de las ciencias sociales», postulado que revisaba el conocimiento social en un contexto del pensamiento de América Latina que rozaba con la negación de la razón y el método científico (Sánchez Parga, 2007). La producción de conocimiento ponía énfasis en la inducción, lo que Lyotard (1986) denominó «el fin de los metarrelatos» para destacar la descripción de lo local, el análisis comenzaba desde la misma realidad, subrayando el papel activo de los sujetos sobre el papel de las estructuras sociales. De esta forma, se cuestionaba la totalidad social para sobredimensionar los espacios de las partes y fragmentarios del mundo social.

El posmodernismo y los estudios culturales representaron un cuestionamiento neoliberal a la razón moderna. La crisis del desarrollismo, del socialismo y la arremetida del neoliberalismo los llevó a formular una «crítica de la matriz iluminista» (Hopenhay, 1992, p. 140). El posmodernismo y los estudios culturales exigían un nuevo discurso de la idea del progreso, dejaba de lado el relato desarrollista y la razón iluminista. En cambio, posmodernismo y los estudios culturales se imbricaban de la hegemonía de la voluntad individualista y de la "mano invisible del mercado", que en América Latina significaba una reverencia por lo inmediato y lo provisional. El proyecto epistémico pasaba de una modernización desarrollista dirigida a una modernización posmoderna neoliberal.

2 Puede consultarse los trabajos tempranos de Eduardo Grüner (1998) y (2002), Roberto Follari (2001) y (2002), Carlos Reynoso (2000), Aníbal Quijano(1990), Heinz Sonntang (1988), Orlado Fals Borda (1990), Jorge Vergara y Enrique Gomáriz (1993). 
En segundo lugar, América Latina se abre a nuevos enfoques cognoscitivos, fundados en la redención de la razón y los aportes de la complejidad que ponen en cuestión la hegemonía del modelo de la racionalidad cartesiano-newtoniano, Pablo González Casanova recoge los aportes de las ciencias de la complejidad en Las nuevas ciencias y las humanidades(2004), Humberto Maturana (2002) sistemas autopoiéticos y recientemente cobran impulso las investigaciones de la neurociencia de Antonio Damasio (2009; 2018).

Las ciencias de la complejidad permiten acercarnos a la realidad en sus múltiples determinaciones, abrir las posibilidades infinitas del mundo, reconocer las heterogeneidades dentro de la totalidad, destacar las redes de los individuos y el sistema, del continuo proceso interrelacionado entre lo vivo, lo químico, lo físico de la tierra y de franquear la inmensidad y la incertidumbre del universo. Desarrolla una crítica radical a la visión mecanicista de las corrientes posmodernas y la práctica más difundida del «empirismo puro» en las ciencias sociales (Giddens, 2000, p.13), que fragmenta y describe la realidad a partir de la "primacía determinante sobre todas y cada una de las partes», que rehusaban considerar la importancia de la «totalidad histórica-social» (Quijano, 2000). La totalidad histórico-social es un patrón de relaciones sociales articulado por una unidad conflictiva y discontinua entre diversos ámbitos, que produce una configuración heterogénea. Cada ámbito se constituye como un campo de relaciones de poder que guarda relación con el sistema y, a la vez, tiene cierta autonomía relativa en relación al todo, son partes respecto a la totalidad y por ello se mueven según la orientación del conjunto, pero no lo son respecto a los otros componentes, porque cada cual tiene una configuración históricamente diferenciada que, en momentos específicos, pueden llegar a ser contradictorios y, circunstancialmente, de renovación con el conjunto societal. Las realidades sociales se desarrollan en procesos de orden, desorden y organización, que suponen azares, bifurcaciones, múltiples caminos y formas de extinción. De esa manera, la complejidad grafica un futuro indeterminado, donde los equilibrios son más bien las excepciones, la autoorganización como un proceso complejo de la realidad y, por lo tanto, la racionalidad de la complejidad implica que los fenómenos se enfrentan a un conjunto de sucesivas alternativas, no a leyes universales preestablecidas que gobiernan el mundo, lo que Ilya Prigogine denomina el fin de las certidumbres (1997) y González Casanova «la acción en busca de posibilidades» (González Casanova, 2004, p.124).

En la década del sesenta del siglo pasado un punto de inflexión esencial en el discurso epistémico de América Latina es la «teoría cognitiva» de la autopoiesis elaborada por Humberto Maturana y Francisco Valera ${ }^{3}$, que formula una propuesta radicalmente distinta al pensamiento cartesiano-newtoniano. Maturana produce un cambio epistémi-

3 Humberto Maturana (1999). Humberto Maturana y Francisco Varela (2006). Humberto Maturana y Bernhard Pörksen (2004). 
co concluyente con respecto al pensamiento newtoniano que había tenido hegemonía mundial por más de tres siglos en la cognición moderna. La idea cartesiana de mente y cuerpo como ámbitos separados e independientes va a ser superado por la perspectiva sistémica, definiéndolos como dos aspectos complementarios del mismo fenómeno, partes integrantes de la misma evolución de todo ser vivo (Capra y Luigi Luisi, 2014).

Las sociedades y todo ser viviente son sistemas autopoiéticos, «sistemas que se producen a sí mismos continuamente» (Maturana, 2002, p.92), son entidades que se autorganizan y autoproducen simultáneamente. De esa forma, mente y cuerpo no pertenecen a dos entes distintos, son manifestaciones integradas de la renovación/aprendizaje de todas las formas de vida. La mente es un proceso involucrado en la autopoiesis de la vida. El sistema vivo es resultado de un proceso de aprendizaje, la cognición es el modo cómo el organismo autoproduce la vida, desde la célula más simple hasta la forma social más compleja. La existencia del organismo vivo por las interacciones con el entorno se constituye en un proceso cognitivo. El propio patrón de organización del ser vivo no solo determina sus modificaciones, sino que, además, «especifica también qué perturbaciones del entorno» son las que condicionan las modificaciones. El organismo registra sus transformaciones y alteraciones establecidas en función de la experiencia de vivir en un entorno específico, registro que se denomina actos de aprendizaje y permiten que el sistema perdure y siga viviendo, de lo contrario puede perecer. Como las relaciones estrechas de un ser viviente con su contexto son interacciones cognitivas, estas se producen dentro del organismo, van hacia afuera y se proyectan alterando su entorno, para volver a condicionarlo en un proceso de espiral permanente, es la forma cómo el organismo transforma sus relaciones con el ambiente según sus exigencias cognitivas (Maturana y Varela,1980). La cognición en los organismos vivientes no es una copia de la realidad, se organiza en función de las exigencias del organismo para sobrevivir en un entorno, es parte de la evolución biológica de cualquier forma de vida.

Otra perspectiva teórica en el campo de las ciencias sociales que expresa una ruptura profunda con el pensamiento cartesiano-newtoniano, de separación radical de mente y cuerpo, es la neurociencia (Damasio, 2009; 2018). En el ámbito de las ciencias sociales lo resalta Manuel Castells en su trabajo Comunicación y poder (2009) y en América Latina en el campo de la investigación lo subraya Martínez Miguélez (2014). La neurociencia entiende la acción humana como un proceso unitario indisoluble entre las emociones, sentimientos y razonamientos, trastocando profundamente el principio cartesiano del «yo pienso, luego existo» que los disociaba radicalmente en dos dominios separado de lo humano, al restituir la unidad del «yo existo»-siento- y «yo pienso». Para la neurociencia las emociones se encuentran en la base de todo razonamiento y comportamiento social, la estructura del razonamiento de las decisiones suele inclinarse por las informaciones más sentidas. Castells (2009) ha identificado las emociones centrales que impulsan a la búsqueda de las informaciones en la cognición sociopolítica: 
el miedo y la ira en la autoconservación de la vida y, conjuntamente, el entusiasmo y la esperanza en la supervivencia y futuro del comportamiento societal. En ese cuadro, las emociones pueden actuar en forma abierta e inmediata indicando la racionalidad de la conducta social a perseguir y, también, las emociones pueden enmarcar la racionalidad del comportamiento con las informaciones disponibles que indican el conjunto de posibilidades de la decisión a seguir en la conducta humana (Damasio, 2018).

El aporte de Maturana, las ciencias de la complejidad y la neurociencia son fundamentales, generan una profunda «ruptura epistemológica» del discurso moderno cartesiano-newtoniano. Perspectivas, que posibilitan el desarrollo de un nuevo debate de las ciencias sociales.

\section{El «nuevo debate latinoamericano» de las ciencias sociales}

En la última década del siglo pasado emerge "un nuevo debate latinoamericano» que cuestiona el modo eurocéntrico de pensar las ciencias sociales (Quijano, 2014, p.11). América Latina alumbra varias trayectorias de un pensamiento propio que ponen en cuestión la universalidad del saber dominante y abre un momento de disputa epistémico en el patrón moderno tardío. La región rompe con el mono discurso eurocéntrico y se transforma en fuente del pensar, imaginar y producir conocimiento. De las distintas tendencias intelectuales latinoamericanas se destacan la teoría crítica, el neoliberalismo, el neodesarrollismo, los estudios «étnicos» y la colonialidad del poder.

En esa dirección, se subraya la perspectiva neoliberal por su hegemonía cultural mundial. El neoliberalismo busca reconcentrar recursos y poder para el capital internacional, conlleva una creciente liberalización de los mercados, privatización de las empresas públicas y de los recursos naturales, mercantilización de todas las esferas de la vida social y produce el desarrollo exponencial de las desigualdades de la población. Perspectiva en América Latina que después de los noventa ha experimentado una fuerte pérdida de legitimidad y cuestionamiento (Calderón y Castells, 2019).

En Latinoamérica el neoliberalismo asume algunos rasgos específicos que es fundamental destacar, concepción que tuvo su campo de experimentación en Chile (1973) durante el gobierno dictatorial de Augusto Pinochet, solo después pudo instituirse en Inglaterra (1979) de Margaret Thatcher, Estados Unidos (1980) de Ronald Reagan y, posteriormente, se difundió por el resto del mundo. En América Latina desde los ochenta su exponente más importante es el peruano Hernando de Soto que reelabora el discurso neoliberal con La revolución informal (1986), a la perspectiva del individuo libre en el mercado sin las interferencias del Estado, incorpora los derechos de propiedad, la informalidad empresarial y, principalmente, el capitalismo popular. Propuesta 
teórica que permitió asumir la crítica al "análisis eurocéntrico» de los «estudiosos occidentales» que pueden llevar a la «desigualdad arbitrarias e insostenibles» en los países, pero equivocado en su diagnóstico para las poblaciones más pobres y con sectores de informalidad muy extendida especialmente en el tercer mundo, donde uno de las problemáticas esenciales es la existencia de una gigantesca masa inmovilizada de «bienes indocumentados» y la ausencia de mecanismos que faciliten el acceso al capital a las poblaciones desposeídas. En ese sentido, Hernando de Soto $(2015 ; 2016)$ señala que el asunto del desarrollo moderno neoliberal no es "por qué tan pocos tienen tanto" sino, principalmente, "por qué tantos tienen tan poco», no interesa las desigualdades sociales, lo más importante es la extensión del capital y mercado para las poblaciones pobres del mundo.

En general, el neoliberalismo nativo propendió la prioridad de mercados desregulados, sobre todo, emprendedores populares, individualismo y mercantilización, nunca se propuso una sociedad más igualitaria y de creciente democracia. Es decir, desde América Latina la perspectiva neoliberal formuló un camino de crecimiento y modernización económica que «incluyan» lo informal y lo pobre, nunca suscribió las viejas promesas de la modernidad de libertad e igualdad social.

El neodesarrollismo es el discurso que formula la modernización de los países poniendo énfasis en la figura del Estado, la redistribución social, en la crítica al neoliberalismo y asumiendo los valores nativos de cada región (Mahbubani, 2002; 2013), hace eco de las experiencias de Brasil, Bolivia, Ecuador, Venezuela y, de alguna forma, de China, Singapur, Rusia entre otros. El neodesarollismo expresa la crisis de la modernidad en siglo XXI, describe los límites del dominio de los Estados Unidos y del neoliberalismo global que ya no pueden controlar al sistema mundo moderno y señala el ascenso de las nuevas potencias internacionales de China y de Rusia. Formula un camino de «desoccidentalización» (Mignolo, 2014) como una forma de mantenerse en el camino de modernización capitalista, destacando los límites del proceso moderno eurocéntrico, cristiano y de la ilustración impulsado a partir del siglo XVI, que en el periodo actual viene difuminándose y aperturando nuevas vías diferenciadas de modernización capitalista con las experiencias culturales orientales -budismo, eslavismo, islamismo, confucionismo y otras-, andinas y hasta africanas. El neodesarrollismo incorporan aspectos del legado histórico propio, del mundo andino el buen vivir en el Estado Plurinacional, el confucionismo en el Estado Civilizatorio Chino o el islamismo en Singapur. Rechaza las formas abiertas de racismo occidental y posibilita la enmergencia de una «burguesía global de color» que intenta liderar el proceso. La «desoccidentalización» significa el tránsito de un mundo monocéntrico, europeísta y capitalista hacia un orden global policéntrico y capitalista, se puede ser moderno con valores multiculturales. Pareciera que en América Latina la expresión teórica mayor es la del boliviano Álvaro García Linera (2013), 
Sin embargo, en América Latina el camino neodesarrollista se encuentra marcado, en gran parte, por la "corupción estatal» y la predominancia de una economía «extractivista informacional» (Calderón y Castells, 2019), con la consiguiente destrucción de territorios nativos que tienen en el caso boliviano la marcha en defensa del TIPNIS su mayor resistencia. En sus vertientes más consumadas de Asia el neodesarrollismo puede llevar a la negación de la democracia y de las libertades (López, 2012, pp.74-79 y Castells, 2010). En general, la perspectiva neodesarrollista busca desvincularse del diseño global neoliberal y mantenerse en la modernización capitalista, recalcando sus nexos con los valores locales, aunque atentando gravemente contra la naturaleza y dejando de lado las libertades democráticas.

Es importante destacar el pensamiento crítico, discurso que cuestiona el orden establecido o algunos de sus aspectos fundamentales en función de los valores de igualdad social, libertad y justicia (Altamirano et al, 2009). El actual pensamiento crítico es fruto de la devaluación de la perspectiva socialista que alcanza su punto álgido en 1989, con la caída del Muro de Berlín. Es más, desde fines de los ańos ochenta en Latinoamérica toda forma de pensamiento crítico de la sociedad entró en rápida decadencia y disgregación, sin mayor debate alguno, en gran parte definido por su carácter eurocéntrico (Santos, 2010) y por la hegemonía del discurso neoliberal (Quijano, 1995). En la actualidad, el pensamiento crítico bosqueja algunas ideas que ponen en cuestión algunos nudos centrales de la modernidad, en un esfuerzo por reencontrarse con su gran tradición teórica, se caracteriza por el predominio del pensamiento ensayístico ecléctico, con posiciones que pretenden ir más allá del marxismo, tratando de incorporar ideas contestarias de los pueblos de África, América Latina y Asia y en la perspectiva de superación de las viejas ideas eurocéntricas ${ }^{4}$.

En esas condiciones, se subrayan los trabajos de Thomas Piketty El capital del siglo XXI (2015) y de James Lovelock La venganza de la tierra. La teoria de la Gaia y el futuro de la humanidad (2007), pensadores que mejor expresan la actual situación transicional de la teoría crítica. Thomas Piketty de manera definitiva ha develado las falacias a teóricas del neoliberalismo, demuestra analíticamente que el «1\% más rico» es resultado de la hegemonía de la modernidad global, sistema que únicamente lleva la expansión de las desigualdades extremas, $y$, en ese contexto, para poder sobresalir o vivir en ese mundo quedan únicamente dos caminos ser "genio o un corrupto» (2014), para las mayorías apelar a los recursos de la violencia, narcotráfico y criminalidad se vuelven

4 Se destaca, la teoría del acontecimiento de Badiou, la perspectiva de Pierre Bourdieu, el poscolonialismo de Bhabha y Spivack, el neomarxismo de Holloway, la crítica de Chosnky, el lacanianismo de Žižek y el Imperio y la Multitud de Hardt y Negri, la teoría de de sociedad red de Castells y la sociedad líquida de Bauman entre otros. Véase Claudia Luz Piedrahita Echandía, Álvaro Díaz Gómez y Pablo Vommaro (Compiladores): Pensamientos críticos contemporáneos: Análisis desde Latinoamérica, Universidad Distrital Francisco José de Caldas - CLACSO, Bogotá, 2015. Göran Therborn: «Después de la dialéctica la teoría social radical en un mundo poscomunista», New Left Review N ${ }^{\circ}$ 43. Marzo/abril, 2007, pp. 59-106. 
estructurales, partes inherentes de la sociedad. El trabajo de Thomas Piketty es uno de los más debatido a nivel mundial, desarrolla algunas ideas formuladas y aceptadas por los pensadores críticos de la última parte del siglo pasado e inicios del siglo XXI, su mayor aporte intelectual consiste en la explicación de las limitaciones del neoliberalismo y con las contundencias irrefutables de las pruebas fundadas en grandes series históricas que permiten descarnar la naturaleza de la modernidad capitalista del siglo XXI. En ese sentido, la obra de Thomas Piketty renueva analíticamente la teoría crítica, posibilita pensar más allá del neoliberalismo y permite imaginar una sociedad diferente.

Por otra parte, el científico James Lovelock en La teoría de Gaia, formulada a fines de los ańos sesenta, señala que el planeta Tierra es un sistema autorregulado entre lo biológico, geográfico y químico, forma un complejo entrelazamiento de estructuras de seres vivos y no vivos que se conforman mutuamente en un proceso unitario, del cual la vida humana es uno de sus componentes. Parecería que ese equilibrio autopoético de la Tierra se ha roto por la influencia depredadora de la modernidad de los últimos cinco siglos, poniendo en peligro toda forma de existencia en los próximos 100 años. Basta señalar que actualmente está en desarrollo la sexta extinción a gran escala de la vida en la tierra, la ratio es hasta 100 veces más alto que la tasa natural (Ceballos et al, 2015) y que los últimos años han sido el de mayor temperatura de los que se tiene registro (NASA, 2015). Destacando que, a diferencia de periodos históricos pasados de rupturas del equilibrio autogenerado de la Tierra fue producto de los propios fenómenos de la naturaleza, en cambio el momento presente es resultado directo de la acción humana, de ahí su carácter profundamente violento y destructivo.

Los estudios "étnicos» son otra perspectiva que irrumpe con «mucha vitalidad» frente al discurso del pensamiento eurocéntrico, se desenvuelven en algunas asignaturas y departamentos de las Universidades en los Estados Unidos5. Los estudios "étnicos» son expresión de la presión de los movimientos de la sociedad de fines de la década de los sesenta, producto de la discriminación y la afirmación de la identidad de los grupos segregados en Norteamérica como los negros, indígenas, puertorriqueños, mujeres, chicanos, chinos y latinos. Estudios que nacen en el contexto de los «estudios de área» impulsados por las políticas estatales norteamericanas para conocer la diversidad regional del tercer mundo con la intención de propiciar las estrategias necesarias para extender la dominación durante el periodo de la guerra fría (Moraña, 2014). En los últimos ańos los estudios «étnicos» por la influencia de los «Filósofos 'latinos' en Estados Unidos» evolucionan hacia posiciones cercanas con la opción de la descolonialidad (Dussel, 2007 y Mignolo, 1996). Los estudios «étnicos» a partir de una "epistemología fronteriza», de las subjetividades de las poblaciones, marginadas, immigrantes y de la necesidad por «re-existir» subrayan la importancia de elaborar un pensamiento propio,

5 Wallerstein (1999), Maldonado-Torres (2006) y Grosfoguel (2013). 
como condición indispensable para empoderar reflexivamente a las comunidades racializadas, reforzar sus identidades y ganar libertades (Mignolo, 2015).

La propuesta central de los estudios «étnicos» es debatir un conocimiento desde los sujetos inferiorizados y fronterizos, contribuyendo a desarrollar una crítica al eurocentrismo en el mismo centro donde se produce los significados de la modernidad global y posibilita una epistémica de libertad de los inmigrantes, la etnicidad, género y la tolerancia de todas las minorías sociales. Los estudios «étnicos» irrumpen en el pensamiento contemporáneo revisando los contenidos de nación e identidad, cultura, los cuerpos «de color» y relaciones de género. Expresa una trayectoria epistémica que abre la posibilidad de modificar el carácter de las poblaciones segregadas de simples objetos a sujetos colonializados pensantes y activos. Los estudios «étnicos» buscan la supresión epistémica del imaginario, memoria y conocimiento en función de la producción del constructo de la idea de racialización y de su clasificación de la población en grupos sometidos (Maldonado-Torres, 2006 y Castillo, 2003).

Los estudios "étnicos» han permitido por sus contribuciones la crítica del eurocentrismo, en el develamiento de la hegemonía universal del pensamiento moderno sustentado en la clasificación racial/cultural y de género de los grupos de inmigrantes, racializados, marginados y sometidos dentro del patrón de poder en los Estados Unidos.

Finalmente, la teoría de la colonialidad del poder es el discurso latinoamericano más integral frente al universalismo europeizado. La colonialidad del poder se relaciona con la elaboración de una teoría para comprender América Latina como parte constitutiva de la modernidad mundial y su devenir. La colonialidad del poder significa el desarrollo de una teoría que explica la modernidad y delinea una posible alternativa ${ }^{6}$. Después de un largo período tenemos una propuesta teórica integral sobre la modernidad global elaborada desde los margenes del pensamiento eurocéntrico. Teoría que marca un hito central en la explicación de la sociedad contemporánea, que no pretende exclusividad alguna, solamente traza un punto de partida abierto al debate y la investigación.

La teoría de la modernidad y colonialidad explica que desde la conquista de América se genera un inédito patrón de poder históricamente particular que integra dos aspectos imbricados, un inédito proceso de explotación fundado en la hegemonía del capital y en un nueva dinámica de dominación basada en la inferiorización racializada de la población, que se constituyen sobre la superioridad universal de la episteme de Europa occidental. Patrón de poder moderno y de colonialidad que tuvo su desarrollo bajo el dominio español en los siglos XVI y XVII, su consolidación con la supremacía holan-

6 Puede consultarse Quijano (2014b), Palermo y Quintero (2014), Mignolo (2003), Mejía (2014) y Germaná (2010). 
desa y francesa en el siglos XVIII, inglesa en el XIX y el poderío norteamericano a partir del siglo XX Quijano ( 2011).

La modernidad/colonialidad es un patrón de organización de la sociedad que convierte la «vida humana desechable» y la naturaleza en «desechable», porque las transforman en objetos mercantilizadas solo para ser explotadas y dominadas por la hegemonía del capital y la precarización e inferiorización de las mayorías poblacionales (Mignolo, 2006). En ese sentido, la racialización, no solo tiene que ver con el color de piel, es esencialmente la capacidad de control del pensamiento de las gentes, de clasificación social para poder dominarlos recurriendo a la inferiorización, porque no se pueden someter y dominar a los iguales. Se organiza una estructura de dominación social basada en la colonialidad, en función de la inferiorización de las personas, que las convierten en seres no dignos de ser humanos, subhumanos, bárbaros, indígenas, negros o mestizos desprovistos de derechos que es necesario civilizar, para lo cual hay que someterlos y en caso de resistencia aniquilar. Modernidad y colonialidad son aspectos complementarios de una misma unidad global.

Precisamente, la modernidad global se encuentra en una gran encrucijada, sin precedentes históricos, presionada por el crecimiento exponencial de la desigualdad social, la precarización laboral y la inferiorización de las poblaciones (Touraine, 2016, p.46). A partir de las últimas décadas del siglo XX opera un proceso de revolución de la automatización y de la inteligencia artificial en los procesos productivos y reorganización del trabajo, modificando drásticamente el sistema moderno al limitar la producción masiva del trabajo asalariado, lo paradójico es que ocurre cuando se produce más empleo y riqueza que en cualquier otro momento de la historia (Standing, 2016). El desarrollo de la modernización neoliberal tiende a generalizar la colonialidad de sus poblaciones replanteando que la reproducción del patrón moderno capitalista discurra más por caminos de la inferiorización social, precarización laboral y trabajo forzado. El resultado de la modernización neoliberal es la brutal concentración de riquezas y recursos que llevan a la exponenciación de la desigualdad social extrema (Piketty, 2015), únicamente 7 personas monopolizan el equivalente de la riqueza que produce el $50 \%$ de la población de la Tierra (Rifkin, 2018).

La modernidad desarrolla el Estado-nación como forma de centralización y articulación de toda la vida social bajo el control de la autoridad pública. Sin embargo, con la expansión de la globalización ha llevado a la pérdida de soberanía de los países y de los derechos ciudadanos por la re-privatización del poder en un «bloque imperial mundial» (Quijano, 2001), conformado por la trama de los países hegemónicos, entidades supranacionales y las grandes corporaciones internacionales, compleja red de poder que viene redefiniendo el papel del Estado-nación por la reconcentración de la autoridad colectiva en el poder de una élite a escala planetaria. Paralelamente, el proceso del precarización e inferiorización condiciona que los derechos sociales se limiten a las capas 
más cercanas al poder y el Estado se vaya transformando en una entidad excluyente, de dominación para las masas por la hegemonía de los mecanismos de «apropiación / violencia» (Santos, 2010, pp.20-30).

Los fundamentos del patrón de poder moderno y de colonialidad conllevó nuevas relaciones intersubjetivas. El eurocentrismo es el imaginario social, la memoria histórica y la perspectiva de conocimiento que permite organizar todas las subjetividades en un gran discurso universal que tienen su centro de poder mayor a Europa y Estados Unidos, que se imponen conquistando, subordinado e invisibilizando a todas las demás formas de pensamiento. El eurocentrismo es la producción del conocimiento basada en la concepción de las relaciones de superioridad/inferioridad de los países metropolitanos -junto a las élites criollas- sobre las poblaciones nativas según la idea de la existencia de diferencias naturalizas de etnicidad y la raza. Patrón histórico de poder que se universaliza a partir de la conquista del nuevo mundo y que dio origen a las sociedades contemporáneas y de América Latina (Mejía, 2014).

Propuestas de América latina que permiten configurar una teoría más allá de la modernidad y colonialidad global. Una teoría sistémica de descolonialidad que posibilita gestar un nuevo horizonte de sentido donde la razón solo pueda imaginarse con los postulados de una sociedad como parte de la naturaleza y de igualdad social y libertad entre las personas.

\section{Notas finales}

El estudio destaca el desarrollo de las ciencias sociales contemporáneas en América Latina y subraya la originalidad del continente en la gestación de propuestas teóricas, en particular de la colonialidad del poder, para comprender el mundo moderno.

Las ciencias sociales de América Latina franquean una dinámica de mutaciones condicionadas por la constitución del camino laberíntico de la modernidad global. De la crisis a la emergencia de un nuevo debate en las ciencias sociales de América Latina se encuentran definidos esencialmente por la revisión y crítica de los fundamentos básicos de las perspectivas teóricas, en particular del propio logos de la modernidad.

La revisión del conocimiento social actual se formula como una crítica de la subjetividad moderna, desatada por las mutaciones de la globalización neoliberal, cuyas limitaciones envuelven los principios epistemológicos de la sociedad capitalista. En ese sentido, el conocimiento social se relaciona estrechamente al devenir de la modernidad.

Además de presentar un itinerario de los principales constructos conceptuales de las ciencias sociales de América Latina, se apunta a destacar su carácter reflexivo, en la medida que su presencia y desarrollo influyen en la sociedad. Ello supone que el mundo 
social no es solo una estructura definida, sino también es producto y componente de una dinámica de estructuración con el conocimiento.

Ciertamente, el desarrollo de las ciencias sociales de América Latina se distingue por la incidencia de un pensamiento propio y la insurgencia de un contenido crítico de la realidad social. Pensamiento propio que pone en cuestión la universalidad de eurocentrismo y apertura un momento de disputa epistémica en el patrón moderno contemporáneo. Precisamente, el pensamiento crítico de las ciencias sociales de América Latina expresa un discurso sobre las limitaciones del mundo moderno actual y abre las posibilidades de pensar una sociedad más igualitaria y de defensa de la naturaleza.

\section{Referencias}

Altamirano, C. (2009): Encuesta sobre el pensamiento crítico en América Latina. Crítica y Emancipación Revista Latinoamericana de Ciencias Sociales, Año I, No2, Buenos Aires.

Bourricoud, F. (1967): Poder y sociedad en el Perú contemporáneo. Sur: Buenos Aires.

Calderón, F. y Castells, M. (2019): La nueva América Latina. FCE: México.

Capra, F. y Luigi Luisi, P. (2014): A visão sistêmica da vida: uma con-cepçâo uni cada e suas implicaçóes losó cas, políticas, sociais e económicas. Cultrix: São Paulo.

Castells, M. (2010): ¿Democracia en China? La mayoría de la población china es indiferente al tema de la democracia e ignora o critica a Liu Xiaobo, La Vanguardia Internacional, 16 agosto: Barcelona. http://www.lavanguardia.com/internacional/20101016/54023439474/ democracia-en-china.html

Castells, M. (2009): Comunicación y poder. Alianza: Madrid.

Castillo, D. (2003): Los 'nuevos' latinos y la globalización de los estudios literarios. Boris Muñoz y Silvia Spitta, eds. Más allá de la ciudad letrada: Crónicas y espacios urbanas. Instituto internacional de literatura iberoamericana: Pittsburgh.

Ceballos, G.; Ehrlich, P.; Barnosky, A.; García, A.; Pringle, R. ; Palmer, T. (2015): Accelerated modern human-induced species losses: Entering the sixth mass extinction, Science Advances, Vol. 1, No 5. https://advances.sciencemag.org/content/1/5/e1400253

Cotler, J. (1978): Clases, estado y nación en el Perú. IEP: Lima.

Damasio, A. (2009): En busca de Spinoza. Neurobiología de la emoción y los sentimientos. Crítica: Barcelona.

Damasio, A. (2018): El error de Descartes. La emoción, la razón y el cerebro humano. Planeta: Barcelona.

Dussel, E. (2007): Política de la liberación. Historia mundial crítica. Editorial Trotta: Madrid.

Fals Borda, O. (2003): Ante la crisis del país. Ideas-acción para el cambio. El Áncora Editores / Panamericana Editorial: Bogotá. 
Follari, R (2002): Teorías débiles (para una crítica de la deconstrucción y de los estudios culturales). Homo Sapiens: Rosario.

Follari, R. (2001): Estudios culturales, transdisciplinariedad e interdisciplinariedad (¿hegemonía en las ciencias sociales latinoamericanas?), Utopía y Praxis Latinoamericana, Año 6, N 14 , Maracaibo, pp. 40-47.

García Canclini, N. (1993): Introducción: antropología y estudios culturales Alteridades, Año 3, No 5, pp. 5-8. Universidad Autónoma Metropolitana: México,

García Linera, A. (2013): Democracia, Estado y nación. Vicepresidencia del Estado Plurinacional: La Paz.

Germaná, C. (2010): Una epistemología otra: El proyecto de Aníbal Quijano. Nomadas No 32, pp. 77-94: Bogotá.

Geertz, C. (1990): La interpretación de las culturas. Gedisa: Barcelona.

Giddens, A. (2000): En defensa de la sociología. Alianza: Madrid.

Grosfoguel, R. (2013): Los estudios étnicos en Estados Unidos como estudios descoloniales al interior del sistema universitario global occidentalizado, Ra Ximhai, V 9, No 1, pp. 17-34. Universidad Autónoma Indígena de México

Grüner, E. (2002): El fin de las pequeñas historias. Buenos Aires, Paidós.

Grüner, E. (1998): F. Jameson-S. Zizek. Estudios culturales. Reflexiones sobre el multiculturalismo. Paidós: Buenos Aires.

González Casanova, P. (2004). Las nuevas ciencias y las humanidades. De la academia a la política. Anthropos - IIS de la UNAM - Editorial Complutense: Barcelona.

Hopenhay, M. (1992). ¿Pensar lo social sin planificación ni revolución. Revista de la CEPAL, No 48: Santiago.

López, V. (2012): La modernidad de China. Fin del socialismo y desafíos de la sociedad de mercado. Siglo XXI: México.

Lovelock, J. (2007): La venganza de la tierra. La teoría de la Gaia y el futuro de la humanidad. Planeta: Barcelona.

Luhmann, N. (2007). La sociedad de la sociedad. México: Herder y Universidad Iberoamericana. Lyotard, J. (1986): La condición posmoderna. Cátedra: Madrid.

Mahbubani, K. (2013): El nuevo hemisferio asiático. El irresistible desplazamiento global hacia Oriente. Siglo XXI: México.

Mahbubani, K. (2002): ¿Pueden pensar los asiáticos? Siglo XXI: México.

Maldonado-Torres, N.(2006): Pensamiento crítico desde la subalteridad: los estudios étnicos como ciencias descoloniales o hacia la transformación de las humanidades y las conciencias sociales en el siglo veintiuno, Revista Interamericana de educación de Adultos CREFAL, No 1, pp. 143 -165: México.

Maturana, H. (2002): Transformación en la convivencia. Dolmen Ediciones: Santiago.

Maturana, H. (1999): Biología de la cognición y epistemología. Universidad de la Frontera: Temuco. 
Maturana, H. y Varela, F. (2006): De máquinas y seres vivos. Autopoiesis: la organización de lo vivo. Editorial Universitaria: Santiago.

Maturana, H. y Varela, F. (1980): Autopoiesis and Cognition. The realization of the living. Reidel Publishing Company: Boston.

Maturana, H. y Pörksen, B. (2004): Del ser al hacer. Los orígenes de la biología del conocer. J.C. Sáez: Santiago.

Martínez, M. (2014): Nuevos fundamentos en la investigación cientifica. Trillas: México.

Martínez, M. (2009): El paradigma emergente. Hacia una nueva teoría de la racionalidad cientifica. Gedisa: Barcelona.

Martín-Barbero, J. (2001): Modernidad, posmodernidad, modernidades. Discursos sobre la crisis y la diferencia. En Revista Digital Dissens, N¹, Universidad Javeriana, p. 9. http://www. javeriana. edu.co/pensar/dissens16. html

Mejía, J. (2016): América Latina, modernidad y conocimiento. El desarrollo de otro discurso epistémico. UNMSM: Lima.

Mejía, J. (2014): Colonialidad y des/colonialidad en América Latina. Elementos teóricos, Aníbal Quijano: Des/colonialidad y bien vivir. Un nuevo debate en América Latina. Editorial URP: Lima.

Mejía, J. (2002): Problemas metodológicos de las ciencias sociales en el Perú. UNMSM: Lima.

Mills, C. R. (1986): La imaginación sociológica. FCE: México.

Mignolo, W. (2015): Habitar la frontera: sentir y pensar la descolonialidad (Antología, 19952014). CIDOB: Barcelona.

Mignolo, W. (2014): Prefacio, Zulma Palermo y Pablo Quintero (Compiladores): Aníbal Quijano. Textos de fundación. Ediciones del Signo: Buenos Aires.

Mignolo, W.(2012): Hacia la cartografía de un nuevo mundo: pensamiento descolonial y desoccidentalización (un diálogo con Walter Mignolo). Entrevista realizada por Francisco Carballo. Otros Logos. Revista de Estudios Críticos, № 3, Universidad Nacional de Camahue, pp. 263-264.

Mignolo, W. (2006): El giro epistémico descolonial: la contribución de Aimé Césaire a la geopolítica y biopolítica del conocimiento, Aimé Césaire: Discurso sobre el colonialismo. Madrid: Akal, pp.197-221.

Mignolo, W. (1996): Posoccidentalismo: las epistemologías fronterizas y el dilema de los estudios (latinoamericanos) de áreas. Revista Iberoamericana, № 176-177, Universidad de Pittsburg, pp. 679-696.

Moraña, M. (2014): Inscripciones críticas. Ensayos sobre cultura latinoamericana. Editorial Cuarto Propio: Santiago.

Morin, E. (1995): Sociología. Tecnos: Madrid.

NASA, NOAA Analyses Reveal Record-Shattering Global Warm Temperatures in 2015, http:// www.nasa.gov/press-release/nasa-noaa-analyses-reveal-record-shattering-global-warm-temperatures-in-2015 
Palermo, Z. y Quintero, P. (2014): Anibal Quijano. Textos de fundación. Ediciones del Signo: Buenos Aires.

Piedrahita, C., Díaz, A. y Vommaro, P. (Compiladores) (2015): Pensamientos criticos contemporáneos: Análisis desde Latinoamérica. Universidad Distrital Francisco José de Caldas CLACSO: Bogotá.

Piketty, T. (2015): El capital del siglo XXI. FCE: México.

Piketty, T. (2014): Utilizando una obra de Balzac. '¿Triunfar hoy? O eres un genio o un corrupto': Piketty explica el siglo XXI, El Confidencial 29 de abril. http://www.elconfidencial.com/alma-corazon-vida/2014-04-29/ triunfar-hoy-o-eres-un-genio-o-un-corrupto-el-guru-de-moda-explica-el-futuro_122640/

Prigogine, I. y Stengers, I. (2002): La nueva alianza. Metamorfosis de la ciencia. Alianza: Madrid. Prigogine, I. (1997): El fin de las certidumbres. Taurus: Madrid.

Quijano, A. (2014a): Des/colonialidad y bien vivir. Un nuevo debate en América Latina. Editorial URP: Lima.

Quijano, A. (2014b): De la dependencia histórico-estructural a la colonialidad/descolonialidad del poder. CLACSO: Buenos Aires.

Quijano, A. (2011): Bien vivir: entre el 'desarrollo' y la des/colonialidad del poder. Ecuador Debate, No 84, pp. 77-87. Quito.

Quijano, A. (2001): Entre La Guerra santa y la cruzada. América Latina en Movimiento, $\mathrm{N}^{\circ} 341$, Quito.

Quijano, A. (2000): Colonialidad del poder y clasificación social. Journal of World-Systems Research, Vol. XI, No 2, pp. 342-386. State University of New York Binghamton

Quijano, A. (1995): El fujimorismo y el Perú. SEDES: Lima.

Quijano, A. (1992): Profesión y oficio de la sociología. Universidad y Sociedad, año 2, No 4, 24-25: Lima.

Quijano, A. (1990): Notas sobre los problemas de la investigación social en América Latina. Revista de Sociología, Vol. 6, No 7, UNMSM: Lima.

Quijano, A. (1982): Sociedad, poder y sociología en el Perú . I Congreso Peruano de Sociología: Huacho.

Quijano, A. (1981): Sociedad y sociología en América Latina (1981). Revista de ciencias Sociales, Vol. XXIII, No 1-2. Universidad de Puerto Rico.

Quijano, A. (1967): Naturaleza, situación y tendencias de la sociedad peruana actual. Pensamiento Crítico: La Habana.

Quijano, A. (1965): Imagen y tareas del sociólogo en la sociedad peruana. Letras, Revista de la Facultad de Letras. UNMSM: Lima.

Rifkin, J. (2018): La tercera revolución industrial. Santa Fe Debates Ideas. https://www.youtube. $\mathrm{com} /$ watch?v=yKB1 fuxCzoM

Reynoso, C. (2000): Apogeo y decadencia de los estudios culturales. Una

visión antropológica. Gedisa: Barcelona. 
Santos, B. de S. (2010): Refundación del Estado en América Latina. Perspectivas desde una epistemología del Sur. IIDS - Programa Democracia y Transformación Global: Lima.

Santos, B. de S. (2006): Conocer desde el Sur. Para una politica emancipatoria. UNMSM Programa de Estudios sobre Democracia y Transformación Global.

Sánchez Parga, J. (2007): Una «Devastación de la inteligencia». Crisis y crítica de las ciencias sociales. Abya- Yala: Quito.

Standing, G. (2016). El precariado y la lucha de clases. Sin Permiso: república y socialismo también para el siglo XXI, No15 (Segunda época), pp. 87-102.

Sonntang, H. 1988. Dudalcertezalcrisis. La evolución de las ciencias sociales en América Latina. Caracas: UNESCO - Nueva Sociedad.

Soto, H. de (2016) El 'impasse' mexicano del Santo Padre. El Comercio, Lima, Portafolio, 14 de febrero de 2016, pp. 6-7.

Soto, H. De (2015): Los pobres frente a Piketty, El País, 3 de mayo 2015, http://economia. elpais.com/economia/2015/04/29/actualidad/1430325144_581940.html

Soto, H. de (1986): El Otro Sendero. La revolución informal. El Barranco: Lima.

Therborn, G. (2007): Después de la dialéctica la teoría social radical en un mundo poscomunista. New Left Review No 43. Marzo/abril, pp. 59-106.

Touraine, A (2016): El fin de las sociedades. FCE: México.

Torres-Rivas, E. (2008): Centroamérica: entre revoluciones y democracia. CLACSO - Signo del Hombre: Bogotá.

Vergara, J. y Gomáriz, E. (1993): Teoría, epistemología y poder en la sociología latinoamericana de los noventa. Un análisis desde la perspectiva de su crisis teórica, en FERMENTUM. Revista Venezolana de Sociología y Antropología, Año 3, No 6 y 7, pp. 180-181. Mérida.

Wallerstein I. (2004): Capitalismo histórico y movimientos antisistémicos. Un análisis del sistemamundo. Akal: Madrid.

Wallerstein, I. (2001): Conocer el mundo, saber el mundo: el fin de lo aprendido. Una ciencia social para el siglo XXI, Siglo XXI - UNAM: México.

Wallerstein, I. (1999): Impensar las ciencias sociales. Siglo XXI - UNAM: México. 